\title{
EFFECTS OF SELECTED WARM MIX ASPHALT ADDITIVES ON VISCOSITY PROPERTIES OF BINDER
}

\author{
${ }^{* 1}$ Bekir Aktaş, ${ }^{2}$ Şuayıp Aytekin and ${ }^{3}$ Şevket Aslan \\ ${ }^{1,3}$ Department of Civil Engineering, Erciyes University, Kayseri, Turkey \\ ${ }^{2}$ Kayseri 6th Regional Directorate of the General Directorate of Highways, Turkey
}

\begin{abstract}
:
Asphalt industry has spent great effort to reduce mixing and compaction temperatures of the asphalt mixture because of increasing emission ratios and energy costs. The production of Warm Mix Asphalt (WMA) is related to attaining proper viscosity value of the binder to increase aggregate-binder bonding and compaction of the mixture at lower temperatures. The most important advantages of WMA are lower energy consumption and less pollution. Generally, the production temperature of the asphalt mixture depends on the asphalt properties. In this study, effects of selected warm mix asphalt additives of a certain amount by weight are investigated in terms of viscosity in a Brookfield Rotational Viscometer. The reducing viscosity of the binders will increase production and compaction ability of the mixtures. Also, it will allow to reduce mixing and compaction temperature. Therefore, with the decreased cooling rate asphalt mixtures can haul longer distances and give more time for site construction. The findings of this study show that under the same rotational speed viscosity decreases when additives are used.
\end{abstract}

Key words: Asphalt, Viscosity, WMA Additive

\section{INTRODUCTION}

In recent years, warm mix asphalt (WMA) is becoming more popular in asphalt technology. WMA technology has a lot of benefits such as economic and environmental. The most important advantages of WMA are lower energy consumption and less pollution. Firstly, WMA technology was developed in the 1990s. The ingredients have been tested in Germany and Norway by WAMFoam technology (Dubravský \& Mandula, 2015). WMA mixtures are produced in the temperature range of $100-140{ }^{\circ} \mathrm{C}$ while temperature range of Hot mix asphalt (HMA) is about $140-190{ }^{\circ} \mathrm{C}$. Generally, the production temperature of the asphalt mixture depends on the asphalt properties. The viscosity of the asphalt plays an important role on WMA mixture temperature(Yi-qiu, Lei, Wei-qiang, \& Meng, 2012). It is significantly important for workability and compatibility of the asphalt mixtures. The reducing viscosity of the binders will increase production and compaction ability of the mixtures. Also, it will allow to reduce mixing and compaction temperature. Therefore, with the decreased cooling rate asphalt mixtures can haul longer distances and give more time for site construction. Various techniques have existed to decrease the asphalt viscosity. The WMA production technologies can be categorized in three groups. These are foaming technologies, organic or wax technologies and chemical additives. All of these products may be combinations

*Corresponding author: Address: Department of Civil Engineering, Erciyes University, Kayseri, Turkey. E-mail address: baktas@erciyes.edu.tr, Phone: +90 3522076666 
each other (Martinsh Zaumanis, 2010). At the foaming technologies, a small amount of water to be injected either into the hot binder, or directly into the mixture. With this method the heat causes the water is evaporated and a large amount of foam created. This foam increases the asphalt volume temporarily and decreases the asphalt viscosity. And so, mixture process ability improved remarkably. Another technology to decrease the production temperature of the asphalt mixture is adding some additives. The additives reduce the viscosity at lower temperatures and so it easy to mix asphalt with the aggregate at a lower temperature. Thus with the use of additives it is possible to lower the mixing and compaction temperature. The most famous additive is powdered synthetic zeolite which has been hydrothermally crystallized. When the additive is added to the mixture the water is released as water vapor and thus cause foaming of asphalt. The binder viscosity at high temperatures is reduced and so it allow to reduction in production and compaction temperature (Dubravský \& Mandula, 2015). In this study viscosity changing of the pure and modified binders containing the warm asphalt additives are investigated by measuring the viscosity in a Brookfield rotational viscometer at different temperatures.

\section{MATERIALS AND METHODS}

\subsection{Materials Used}

As a base binder material B50-70 grades bitumen was used for experimental study. In Turkish Highway Specification B50-70 means the penetration of the asphalt binder at $25{ }^{\circ} \mathrm{C}$ ranging between 50-70 units in 0.1 mm (KTŞ-2013, 2013). As a WMA additive, Evotherm M1 was used for binder modification. Evotherm M1 includes additives to improve coating, surfactants to enhance aggregate-binder adhesion. It also promotes workability and compaction for asphalt mixture. This additive can be added at the asphalt tank or at the mix plant. Another WMA additive used in this study is VIATOP ${ }^{\circledR}$ plus C 25 , which contains $75 \%$ by weight cellulose fibers and 25 $\%$ by weight Fischer-Tropsch-Wax. This product prevents the bitumen or bitumen/filler from draining downward and it also decreases the viscosity values of binder since it includes wax.

\subsection{Experimental Work}

The Viscosity Test and other basic asphalt tests were performed for pure and modified binders. The main issue of WMA technologies is to reduce the asphalt viscosity. The reason is the fact that with the lower suitable viscosity aggregate and binder adhesion and compaction of the mixture can be performed at lower temperatures. Therefore, the viscosity of the binder is very important for a better coating of asphalt on the aggregates. It is very difficult to regulate the mixture temperature in the field so it is very important to study the effect of temperature on the viscosity of the binder. 
Therefore, it can be determined which temperature is possible to mix the asphalt with the aggregates. Also, other additives such as cellulose fiber which is used to prevent draindown problem for SMA mixture can increase the viscosity of the asphalt. Cellulose fiber is most commonly preferred in SMA mixtures. Fibers play an increasingly important role in the asphalt concrete and generally most advanced technology for asphalt currently available including vegetable fibers, polymer fibers and mineral fibers (Qunshan Yea, 2009). The most commonly adopted fibers in SMA mixtures are cellulose fibers. The main component of this fiber is cellulose, a polysaccharide. To stabilize the SMA mixture, very small amount of cellulose fiber, around 0.35 $\%$, is required. For this aim, this study was conducted from $100^{\circ} \mathrm{C}$ to $180^{\circ} \mathrm{C}$ with increments of $5^{\circ} \mathrm{C}$ on WMA additives added samples. The viscosity of asphalt with this additive was compared with the viscosity of virgin asphalt. Figure 1 shows the picture of Evotherm M1, VIATOP ${ }^{\circledR}$ plus C 25 WMA additive and Brookfield Rotational Viscometer respectively.
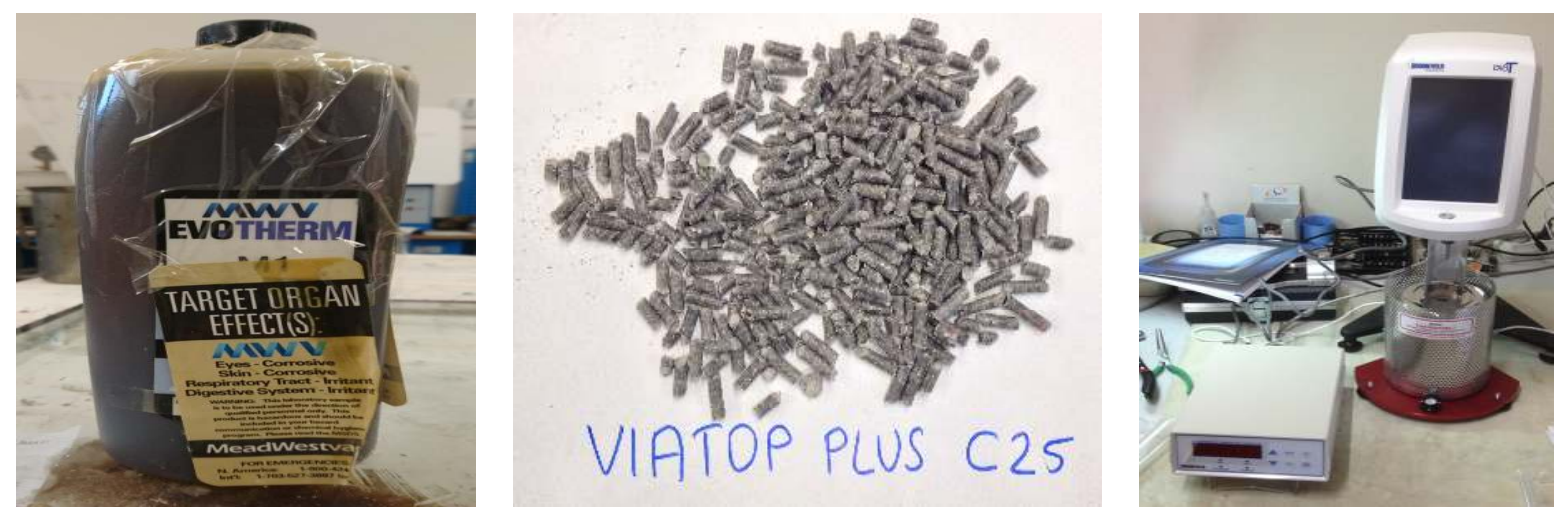

Figure 1. Evotherm M1, VIATOP ${ }^{\circledR}$ plus C 25 and Brookfield Rotational Viscometer

\section{RESULTS AND DISCUSSIONS}

The effect of temperature on the viscosity of modified asphalt samples is determined using the Brookfield rotational viscometer. First of all, pure binder is evaluated in terms of viscosity. In the second step, $0.35 \%$ by weight of VIATOP ${ }^{\circledR}$ plus $\mathrm{C} 25$ is added to the pure binder. In the third step, $0.35 \%$ by weight of VIATOP ${ }^{\circledR}$ plus C 25 and $0.40 \%$ by weight Evotherm M1 is added to the pure binder. All of the three combinations are evaluated under different temperatures. The test results are shown in Fig. 2, Fig. 3 and Fig. 4. It can be seen in these figures that the viscosity of the samples decreases as temperature increases under the standard rotation speed of $20 \mathrm{rpm}$. 


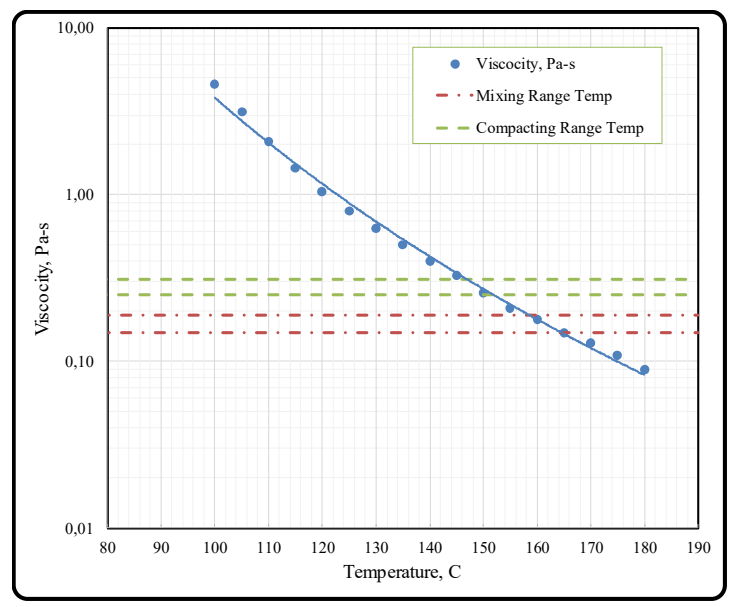

Figure 2. VIATOP ${ }^{\circledR}$ plus C 25

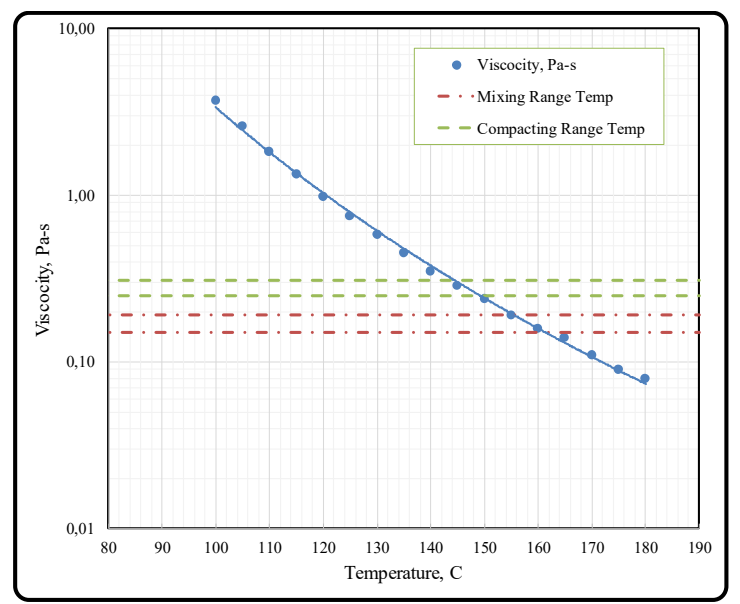

Figure 3. VIATOP ${ }^{\circledR}$ plus C $25+$ Evotherm M1

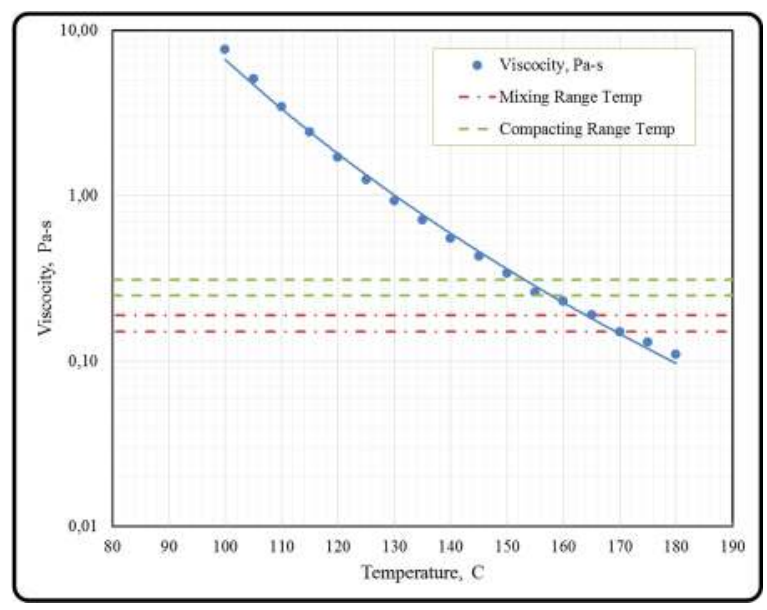

Figure 4. Pure Binder

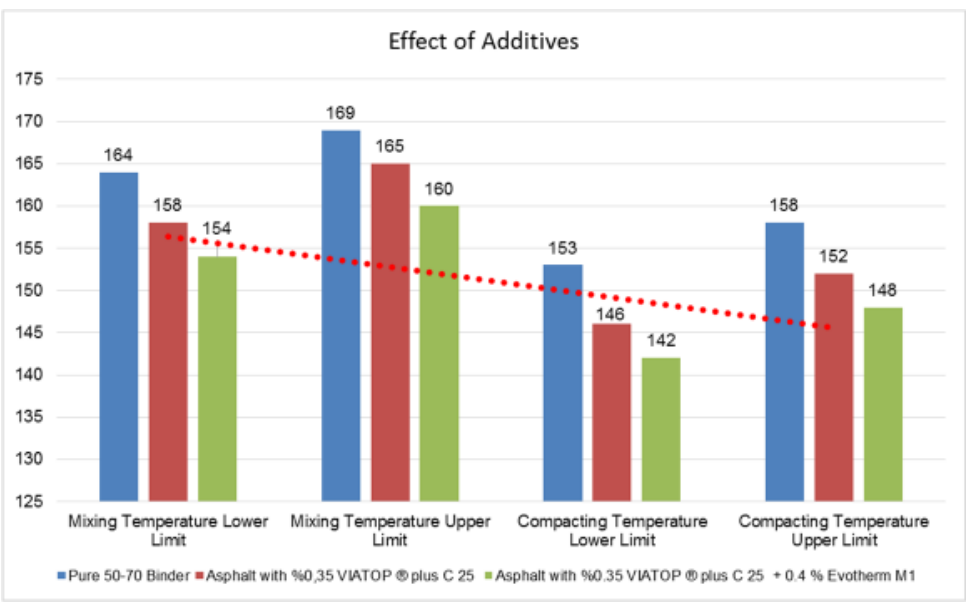

Figure 5. Effect of WMA Additives 
As it is seen in Figure 5, all values of the mixing and compacting temperatures are decreased when the WMA additives are added to the mixtures.

\section{CONCLUSIONS}

This study aims to compare selected WMA additives on asphalt viscosity properties. It is found from Brookfield rotational viscometer test that the viscosity decreases as temperature increases under the same rotation speed. In addition, all of the additives have lower high viscosity than the pure asphalt. Decreasing the viscosity of the binder will make mixing and compacting temperatures possible to be lower comparing to other samples. This experimental study was performed only one ratio of the additives and has been continuing with various additive ratios. Different rates of these additives would effect on the viscosity on the binder.

\section{ACKNOWLEGEMENT}

This study was supported by the Scientific Research Projects Coordination Department of Erciyes University (Project Number: FYL-2018-7942). Authors of this study express their gratitude to ERÜ/BAP for sponsoring the project.

\section{REFERENCES}

Dubravský, M., \& Mandula, J. (2015). Modified Asphalt Binder with Natural Zeolite for Warm Mix Asphalt. Selected Scientific Papers - Journal of Civil Engineering, 10(2). doi:10.2478/sspjce-2015-0018

KTŞ-2013. (2013). Turkish Highway Specification. Republic of Turkey General Directorate of Highways.

Martinsh Zaumanis, R. T. U., Viktors Haritonovs. (2010). Research on Properties of Warm Mix Asphalt. Scientific Journal of Riga Technical University Construction Science, 11, 77-84.

Qunshan Yea, S. W. (2009). Rheological properties of fiber reinforced asphalt binders. Indian Journal of Engineering \& Materials Sciences, 16, 93-99.

Yi-qiu, T., Lei, Z., Wei-qiang, G., \& Meng, G. (2012). Investigation of the effects of wax additive on the properties of asphalt binder. Construction and Building Materials, 36, 578-584. doi:10.1016/j.conbuildmat.2012.06.024 